\title{
A framework for Big Data driven product lifecycle management
}

Yingfeng Zhang, Shan Ren, Yang Liu, Tomohiko Sakao and Donald Huisingh

The self-archived postprint version of this journal article is available at Linköping University Institutional Repository (DiVA):

http:// urn.kb.se/ resolve?urn=urn:nbn:se:liu:diva-139256

N.B.: When citing this work, cite the original publication.

Zhang, Y., Ren, S., Liu, Y., Sakao, T., Huisingh, D., (2017), A framework for Big Data driven product lifecycle management, J ournal of Cleaner Production, 159, 229-240.

https:// doi.org/ 10.1016/j.jclepro.2017.04.172

Original publication available at:

https:// doi.org/ 10.1016/j.jclepro.2017.04.172

Copyright: Elsevier

http:// www.elsevier.com/

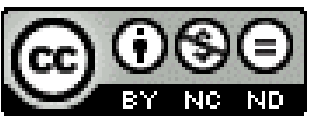




\section{Accepted Manuscript}

A framework for Big Data driven product lifecycle management

Yingfeng Zhang, Shan Ren, Yang Liu, Tomohiko Sakao, Donald Huisingh

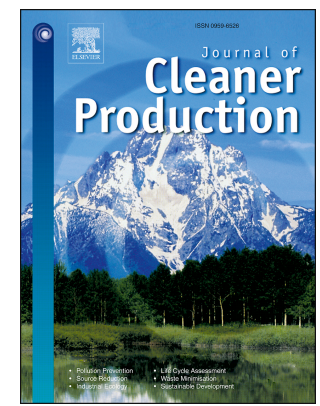

PII: S0959-6526(17)30915-0

DOI: $\quad$ 10.1016/j.jclepro.2017.04.172

Reference: JCLP 9582

To appear in: Journal of Cleaner Production

Received Date: 14 January 2017

Revised Date: 30 March 2017

Accepted Date: 29 April 2017

Please cite this article as: Zhang Y, Ren S, Liu Y, Sakao T, Huisingh D, A framework for Big Data driven product lifecycle management, Journal of Cleaner Production (2017), doi: 10.1016/j.jclepro.2017.04.172.

This is a PDF file of an unedited manuscript that has been accepted for publication. As a service to our customers we are providing this early version of the manuscript. The manuscript will undergo copyediting, typesetting, and review of the resulting proof before it is published in its final form. Please note that during the production process errors may be discovered which could affect the content, and all legal disclaimers that apply to the journal pertain. 


\title{
A framework for Big Data driven product lifecycle management
}

\author{
Yingfeng Zhang ${ }^{\text {a, b }}$, Shan Ren ${ }^{\text {a }}$, Yang Liu ${ }^{\text {c, d, } * *}$, Tomohiko Sakao $^{c}$, Donald Huisingh ${ }^{\text {e }}$ \\ ${ }^{a}$ Key Laboratory of Contemporary Design and Integrated Manufacturing Technology, Ministry of Education, \\ Northwestern Polytechnical University, Shaanxi, P. R. China, 710072 \\ ${ }^{\mathrm{b}}$ Research \& Development Institute in Shenzhen, Northwestern Polytechnical University \\ ${ }^{c}$ Division of Environmental Technology and Management, Department of Management and Engineering, Linköping \\ University, SE-581 83 Linköping, Sweden \\ ${ }^{\mathrm{d}}$ Department of Production, University of Vaasa, PL 700, 65101 Vaasa, Finland \\ ${ }^{\mathrm{e}}$ Institute for a Secure and Sustainable Environment, University of Tennessee, Knoxville, TN, USA \\ * Corresponding Author: zhangyf@nwpu.edu.cn (Y. Zhang), yang.liu@liu.se (Y. Liu)
}

\begin{abstract}
Optimization of the process of product lifecycle management is an increasingly important objective for manufacturing enterprises to improve their sustainable competitive advantage. Originally, this approach was developed to
\end{abstract} integrate the business processes of an organization and more effectively manage and utilize the data generated during lifecycle studies. With emerging technologies, product embedded information devices such as radio frequency identification tags and smart sensors are widely used to improve the efficiency of enterprises' routine management on an operational level. Manufacturing enterprises need a more advanced analysis approach to develop a solution on a strategic level from using such lifecycle Big Data. However, the application of Big Data in lifecycle faces several challenges, such as the lack of reliable data and valuable knowledge that can be employed to support the optimized decision-making of product lifecycle management. In this paper, a framework for Big Data driven product lifecycle management was proposed to address these challenges. Within the proposed framework, the availability and accessibility of data and knowledge related to lifecycle can be achieved. A case study was presented to demonstrate the proof-of-concept of the proposed framework. The results showed that the proposed framework was feasible to be adopted in industry, and can provide an overall solution for optimizing the decision-making processes in different phases of the whole lifecycle. The key findings and insights from the case study were summarized as managerial implications, which can guide manufacturers to ensure improvements in energy saving and fault diagnosis related decisions in the whole lifecycle.

Keywords: Maintenance, Service, Macro level analysis, Micro level analysis, Economic impact

\begin{tabular}{|llll|}
\hline \multicolumn{2}{|l}{ Abbreviations } & & \\
AD & Anomaly detection & MOL & Middle of life \\
BDD-PLM & Big Data driven product lifecycle management & MRO & Maintenance, repair and overhaul \\
BOL & Beginning of life & NoSQL & Not only structured query language \\
BOM & Bill of materials & PDKM & Product data and knowledge management \\
BPRT & Blast furnace power recovery turbine & PEIDs & Product embedded information devices \\
\hline
\end{tabular}




\begin{tabular}{|c|c|c|c|}
\hline CAD & Computer aided design & PLM & Product lifecycle management \\
\hline DDBS & Distributed data base system & $\mathrm{R} \& \mathrm{D}$ & Research and development \\
\hline DSS & Decision support system & RDBMS & Relational database management system \\
\hline DTM & Demand trend mining & RFID & Radio frequency identification \\
\hline ECDM & Energy conversion device manufacturing & RST & Rough set theory \\
\hline ECSS & Energy conversion system service & RTD & Return to depot \\
\hline $\mathrm{EIO}$ & Energy infrastructure operation & SCA & Sustainable competitive advantage \\
\hline EIS & Enterprise information system & SCM & Supply chain management \\
\hline EOL & End of life & SCRU & Supply chain risks and uncertainties \\
\hline HDFS & Hadoop distributed file system & SVM & Support vector machine \\
\hline HoQ & House of quality & TRT & Top-gas-pressure recovery turbine \\
\hline IoMT & Internet of manufacturing things & WIP & Work in process \\
\hline IoT & Internet of things & XML & Extensible markup language \\
\hline MES & Manufacturing execution system & & \\
\hline
\end{tabular}

\section{Introduction}

Big Data refers to a collection of data sets that are too large and complex to efficiently manage and process using traditional technologies and tools (Jacobs, 2009; Zhong et al., 2015b). Since the internet of things (IoT) and advanced information technologies (e.g. radio frequency identification (RFID) tags and smart sensors, which are collectively called product embedded information devices (PEIDs) (Jun et al., 2009)) are widely used in manufacturing enterprises for their daily production and management, the product lifecycle management (PLM) processes produce huge amounts of data. For instance, numerous devices, machines, products, vehicles and manufacturing plants are equipped with RFID and smart sensors. They collect massive quantities of data about themselves and their surroundings. Such data are characterized by high volume, high velocity and high variety, which belong to typical family of Big Data. The era of industrial Big Data has come.

Generally, product lifecycle consists of three stages: beginning of life (BOL) which includes design and manufacturing, middle of life (MOL) which includes use, service and maintenance, and end of life (EOL) when products are disassembled, remanufactured, recycled, reused, or disposed (Jun et al., 2007). The objective of PLM is to provide more product-related information and a shared platform for creation, organization, and dissemination of product-related knowledge across the extended enterprise (Lee et al., 2008). PLM has become a strategy for manufacturing enterprises to improve their sustainable competitive advantage (SCA) (Liu, 2013; Liu and Liang, 2015), which is resulting in the development of enterprise informationalization. Because these new approaches to product lifecycle studies generate such huge quantities of data, the challenge for company leaders is to develop effective and efficient data mining processes to 
mining extracts useful but hidden knowledge and patterns from massive lifecycle data, for the purposes of process control, prediction, and evaluation (Denkena et al., 2014; Köksal et al., 2011).

Therefore, leaders of manufacturing enterprises are becoming increasingly interested in benefiting their companies by effectively using lifecycle Big Data. However, the application of lifecycle Big Data to optimize PLM is facing challenges.

Firstly, product data are relatively complete in BOL supported by the enterprise information system (EIS), such as computer aided design (CAD), supply chain management (SCM) and manufacturing execution system (MES). However, the data gathered during MOL and EOL are non-real time, inaccurate and incomplete, since the owners of the products at those stages are the customers. Thus, decision-making based on incomplete and inaccurate product lifecycle data can result in operational inefficiencies (Jun et al., 2007, 2009).

Secondly, the lifecycle Big Data are characterized by multi-source (e.g. design, production and service data), heterogeneous (e.g. structured, semi-structured and unstructured data), and usually include some "noise" (e.g. incomplete, incorrect and inconsistent data), which might affect the accuracy and reliability of decisions (Chen et al., 2014; Hofmann, 2015). However, current methods are not suitable for eliminating the above noise due to the high complexity of lifecycle Big Data. Consequently, it is difficult to provide uniform data format so that they can be effectively shared throughout all lifecycle stages.

Thirdly, mining the data to find the hidden patterns and knowledge can help to improve decision-making of PLM. However, the patterns and knowledge hidden in lifecycle Big Data are multidimensional (e.g. various management departments, various lifecycle stages) and scattered, which hinders the mining and the application of the patterns and knowledge.

To address these challenges, firstly, literature review on related research was conducted to show knowledge gaps in acquiring and mining Big Data for the whole product lifecycle (see Section 2). Secondly, a framework for Big Data driven PLM (BDD-PLM) was developed and presented with detailed composition of the BDD-PLM and its enabling infrastructures and technologies (see Section 3). Thirdly, in Section 4, a case of an industrial company was selected and analyzed as an application scenario, and to understand how the proposed framework has been introduced to a company to support decision-making in the whole lifecycle, as well as what influences were made on economic benefits of the company. The managerial implications mainly about energy saving and environmental issues were summarized in Section 5. Finally, conclusions were presented in Section 6 to summarize our contributions and to outline the need for future research. 
1

2

3

4

5

6

7

8

9

10

11

\section{Literature review}

This section reviews related studies and is categorized into two aspects: (1) PEIDs and their application in PLM, and (2) Big Data in manufacturing. Knowledge gaps identified from the review are described in the end.

\subsection{Product embedded information devices in product lifecycle management}

The applications of PEIDs (e.g. RFID tags and sensors) in PLM were reviewed from theoretical and practical perspectives.

From the theoretical perspective, an overall framework for RFID applications in PLM was proposed for reducing the inefficiency of lifecycle operations (Jun et al., 2009). The operation scenarios for each application of PEIDs were reviewed. Product data after they are delivered to customers become vague. To overcome the obstacle, a new paradigm for designing and manufacturing via ubiquitous technology was presented (Lee and Suh, 2009). To assist the managers' intentions to improve operational conditions under the adoption of RFID, a framework was developed to support collaboration at different levels within companies (Sari, 2010). By using RFID reader as detecting sensor, an RFID-assisted object tracking system was developed to track the object of assembly line (Wang et al., 2010). Within the RFID-enabled environment, real-time data could be collected. A model for achieving real-time RFID information sharing and inventory monitoring on environmental benefits was developed (Nativi and Lee, 2012). In order to efficiently retrieve the reusable and recyclable items inside a product, Wan and Gonnuru (2013) proposed the use of RFID technology to support disassembly decisions. An architecture of real-time information capturing for the internet of manufacturing things (IoMT) was developed to make better-informed shop-floor decisions (Zhang et al., 2015). A cyber-physical system for manufacturing shop floor based on the RFID was developed to allocate resources timely and to reduce disturbances during production process (Zhang et al., 2016). A RFID-based intelligent decision support system (DSS) architecture was proposed to improve production visibility and decision-making performance in a distributed manufacturing environment (Guo et al., 2015). A framework for IoT-based energy management was developed to support the integration of gathered energy data into a company's production management (Shrouf and Miragliotta, 2015). Consequently, the real-time energy consumption data from manufacturing processes can be analyzed to improve energy-efficiency decision-making.

From a practical perspective, Ford and Toyota automotive companies already used RFID tags in the manufacturing line, and an Italian milling machine company carried out a predictive maintenance by using the PEID that consisting of special sensors and RFID tags (Jun et al., 2007). A warehouse management system with RFID was designed for monitoring the 
consumption of resources and controlling operations (Poon et al., 2009), where data collection and sharing were facilitated by RFID. An architecture of PEIDs application in closed-loop PLM were presented by (Kiritsis, 2011). A real case study that implements a closed-loop PLM solution focusing on EOL of vehicles were introduced to better understand how the proposed architecture can support the EOL decisions. The RFID technology was used for improving the logistical efficiency of the remanufacturing (Ferrer et al., 2011). Adoption of RFID for location identification and remanufacturing process optimization were achieved. A service-oriented framework for RFID-enabled automotive manufacturing solution was developed (Huang et al., 2012). Through the solution, the capability for implementation of advanced production strategies (e.g. just in time and lean manufacturing) can be enhanced. The application of RFID technology in closed-loop supply chains was developed by Kumar and Rahman (2014), and a case study of the inventory control for linen was demonstrated. A method for designing RFID ready facilities was proposed to identify the impact of potential factors related to RFID technology and the physical infrastructure required for RFID implementation in product packaging (Jaggi et al., 2014). The method can help users to avoid unnecessary transportation, thereby saving fuel and reducing pollution.

\subsection{Big Data in manufacturing}

Big Data are highly relevant to our daily life due to the wide use of smart devices (Hazen et al., 2014; Syed et al., 2013). Product lifecycle processes carry a huge number of structured (data of sensors, data of bill of materials (BOM)), semi-structured (user manual published on the web, which is described by extensible markup language (XML)) and unstructured data (audio, video and text). Given the complexity of lifecycle data that influence the decision of manufacturing enterprise, manufacturers need a more effective approach to improve the decision-making process (Auschitzky et al., 2014). Big Data analytics and data mining technology can be used to make a deep analysis into historical lifecycle data, to discover knowledge, and then to optimize the process of PLM. The application of Big Data and data mining technology in each stage of lifecycle is reviewed in subsequent paragraphs.

During BOL, to assist designers on the analysis of house of quality (HoQ) in conceptual design phase, an Apriori-based data mining approach was proposed to extract knowledge from historical data (Zhang et al., 2010). Its availability was illustrated by an electrical bicycle case. To solve scheme evaluation problem in research and development (R\&D) stage, a new integrated design concept evaluation approach based on vague sets was presented (Geng et al., 2010). The proposed approach was applied in the scheme evaluation of a horizontal directional drilling machine. In order to capture upcoming trends of product demand, a demand trend mining (DTM) algorithm for predictive life cycle design was developed to extract knowledge from large-scale data (Ma et al., 2014). The developed 
model was applied to a smart-phone design, which showed that the DTM algorithm could identify a more profitable product design over a product life cycle when compared to traditional design approaches that focuses on the pre-life stage only. The Bayesian algorithm was used to discover unknown priority dispatching rules of single machine through analyses of large amounts of structured or unstructured data (Premalatha and Baskar, 2012). Chen et al. (2012) proposed an integrated model which combining K-means clustering, feature selection, and the decision tree into a single evaluation model to address the performance evaluation of suppliers. The integrated model was illustrated with an empirical case study of a manufacturer. The experimental result indicated that the proposed method was superior to other methods in terms of accuracy. An interactive multi-objective programming algorithm was proposed to deal with the environmental issues in the existing closed loop supply chain network (Garg et al., 2015). With the help of data from a real life case study, a numerical experimentation was used to validate the applicability of the proposed approach. The experimental result showed that with the implication of the extended supply chain, a firm could create a better environmental profile of their product, which eventually results in an increase in the demand for the product. A Big Data approach for logistics trajectory discovery from RFID-enabled production data was proposed to mining the trajectory knowledge (Zhong et al., 2015a). The feasibility of the proposed approach was quantitatively examined by an experiment. The experimental result revealed that the discovered knowledge could be used for logistics planning and production scheduling.

During MOL, the rough set theory (RST) was used to improve the accuracy of the predictive maintenance in non-deterministic cases (Magro and Pinceti, 2009). The proposed method was applied to the predictive maintenance of an intelligent pressure transmitter. A model with neural network algorithm was used for identification and prediction of status patterns of wind turbines (Kusiak and Verma, 2011). In this paper, the prediction models were generated by five algorithms, and the random forest algorithm produced the best prediction results. A data mining approach called anomaly detection (AD) was presented to conduct the fault diagnostics in rolling-element bearing (Purarjomandlangrudi et al., 2014). The performance of the developed algorithms was examined through real data from a failure bearing. Finally, the application of $\mathrm{AD}$ algorithm was compared with the support vector machine (SVM) to investigate the accuracy of this approach, which showed that the AD algorithm has greater precision. A conceptual framework of Big Data strategy in servitization was proposed to undergird the competitive advantage of manufacturing enterprises (Opresnik and Taisch, 2015). The proposed strategy was assessed through three theoretical perspectives. The findings showed that the proposed strategy could create new revenue streams, while opening the possibility to decrease prices for product-services. A Big Data analytics architecture for maintenance processes of complex products was proposed to make better cleaner production decisions based on lifecycle data (Zhang et al., 2017a). A qualitative case analysis was conducted to verify the presented architecture. The results showed that the proposed architecture benefited customers, manufacturers, and 
environment.

Recent advances of Big Data in manufacturing were studied by other researchers. Due to the capability of handling variety of large volume of quickly generated data, Big Data was proposed to address the challenges in industrial automation domain (Leitão et al., 2016). This paper also described the next steps for Big Data adoption in manufacturing.

The potential of Big Data in natural resource management and cleaner production were discussed (Song et al., 2017).

With the goal of minimizing the environmental impact from suppliers to end users, a multi-objective optimization model was proposed to minimize the inherent risk of green supply chain management, and the parameters of the proposed model were identified by Big Data analysis (Zhao et al., 2017). In order to mitigate supply chain risks and uncertainties (SCRU) and ensure sustainable development in light-emitting diode industry, Big Data were used to explore the decisive attributes of SCRU (Wu et al., 2017). A comprehensive literature review of Big Data in PLM were conducted by Li et al. (2015). In this paper, the concept, characteristics, and potential application of Big Data in PLM were analyzed. However, how to employ the concept of Big Data in manufacturing to enhance the intelligence and efficiency of design, production, and service process were not yet been discussed.

\subsection{Knowledge gaps}

From this review, although significant progress has been made in the two research dimensions mentioned above (as shown in Table 1), there are still some gaps that need to be fulfilled:

- In terms of application of PEIDs in PLM, a large number of studies mainly focused on how to apply the PEIDs to one stage of PLM, such as production, disassembly, inventory, and supply chain. The overall solution for the whole product lifecycle was seldom investigated.

- In respect of Big Data and data mining and its application in PLM, most data mining applications only focused on one stage of the lifecycle, such as design, fault diagnosis, and supply chain. Little effort was put on data integration mining and knowledge integration application for the whole lifecycle.

Table 1

Classification and comparison of related studies.

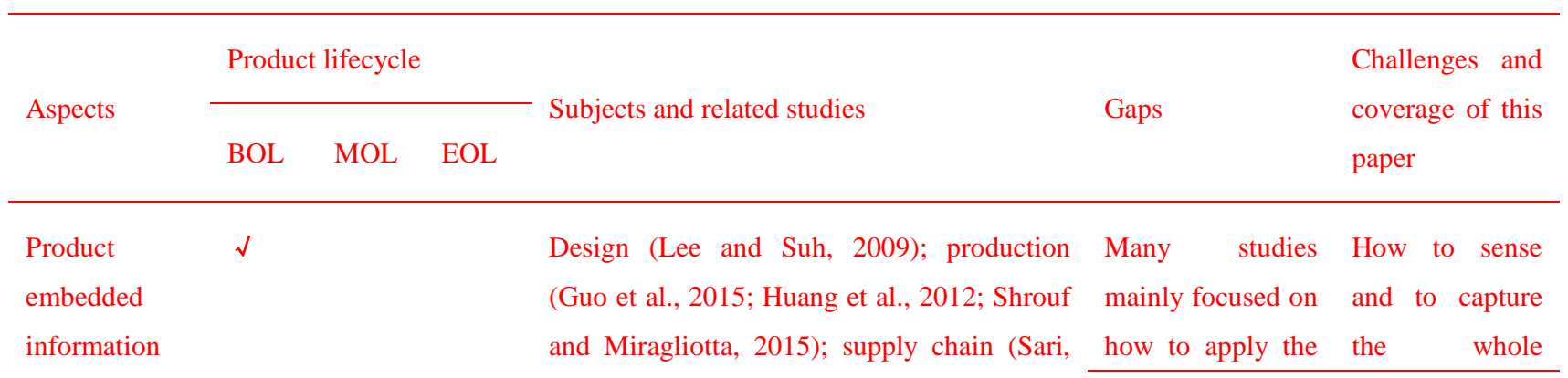




\begin{tabular}{|c|c|c|c|c|}
\hline \multirow[t]{4}{*}{$\begin{array}{l}\text { devices } \\
\text { PLM }\end{array}$} & \multirow{3}{*}{\multicolumn{2}{|c|}{ in }} & & $\begin{array}{l}\text { 2010); assembly (Wang et al., 2010); } \\
\text { inventory monitoring and control (Kumar } \\
\text { and Rahman, 2014; Nativi and Lee, 2012); } \\
\text { shop-floor decisions (Zhang et al., 2016, } \\
\text { 2015); warehouse management (Poon et al., } \\
\text { 2009); packaging (Jaggi et al., 2014) }\end{array}$ \\
\hline & & & & Predictive maintenance (Jun et al., 2007) \\
\hline & & & $\sqrt{ }$ & $\begin{array}{l}\text { Disassembly (Wan and Gonnuru, 2013); } \\
\text { remanufacturing (Ferrer et al., 2011) }\end{array}$ \\
\hline & $\sqrt{ }$ & $\sqrt{ }$ & $\sqrt{ }$ & $\begin{array}{l}\text { PEIDs in the whole lifecycle (Jun et al., } \\
\text { 2009; Kiritsis, 2011) }\end{array}$ \\
\hline
\end{tabular}

Big Data/data $\sqrt{ }$
mining in manufacturing

\section{Product design (Geng et al., 2010; Zhang et} al., 2010); product demand forecasting (Ma et al., 2014); production scheduling (Premalatha and Baskar, 2012); suppliers evaluation (Chen et al., 2012); production logistics planning (Zhong et al., 2015a); production and resource management (Song et al., 2017); supply chain management (Garg et al., 2015; Wu et al., 2017; Zhao et al., 2017)

Predictive maintenance (Magro and Pinceti, 2009; Zhang et al., 2017a); fault patterns recognition (Kusiak and Verma, 2011); fault diagnostics (Purarjomandlangrudi et al., 2014); product servitization (Opresnik and Taisch, 2015)

Review of Big Data in PLM (Li et al., 2015)
PEIDs to BOL of lifecycle Big PLM. The overall solution for Data completely PEIDs and in a timely fashion.

applications in the whole lifecycle is seldom investigated. 

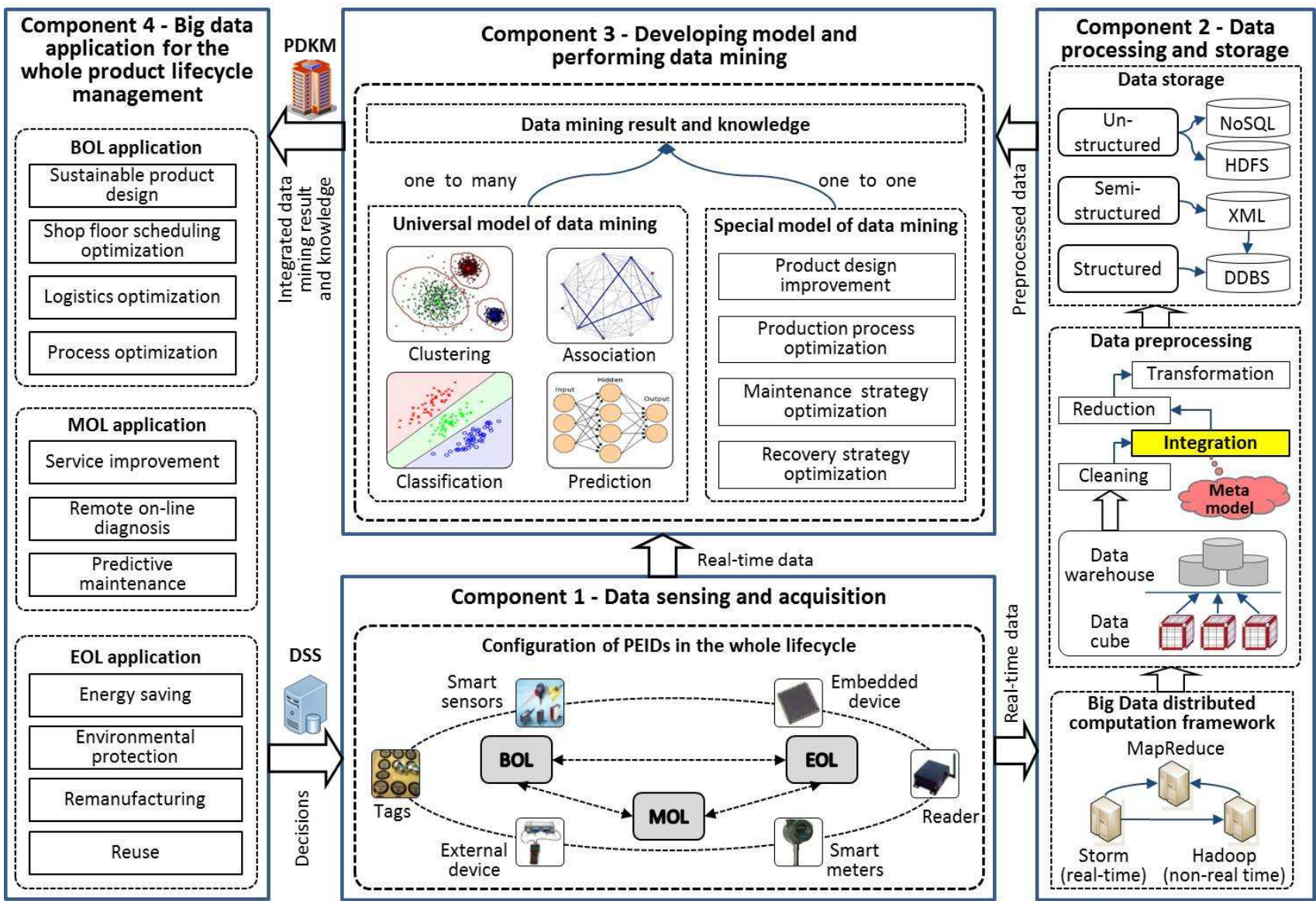

Fig. 1. The designed framework for Big Data driven product lifecycle management.

Under this framework, real-time tracing of the whole product lifecycle status is achieved. Consequently, the whole product lifecycle is dynamically monitored and optimized. The proposed framework consists of four components, namely data sensing and acquisition, data processing and storage, developing the model and performing data mining, and Big Data application for PLM. They are described in the following sections.

\subsection{Data sensing and acquisition}

As shown in the Component 1 of Fig. 1, the configurations of the PEIDs in the whole lifecycle are responsible for enhancing the sensing capability of sensed objects (e.g. materials, machines, operators, products, etc.) The sensed objects are made 'smart' by equipping or embedding the physical objects with PEIDs to achieve a certain degree of intelligence. In this framework, PEIDs such as RFID tags and smart sensors are employed to the whole lifecycle to help to make the objects smart, with the capability of identifying the real-time status of each lifecycle stage (e.g. design, production, maintenance, recycle, etc.). The PEIDs are deployed in several ways. 
During product design stage (BOL), the PEIDs can be expected in the management of technical documents. For example, the passive RFID tags attached to all technical documents enable us to manage a huge number of technical documents in a systematic way and to find necessary information efficiently.

During production stage (BOL), machines of the shop-floor is equipped with a RFID reader. This reader is multi-functional and is responsible for reading the tags/sensors deployed to different objects. Readers are also used at the warehouse for the tools and materials, and at the key management points (e.g. entrances to the shop-floor). Operators have their staff cards that are read and written by the RFID terminals. In addition, critical tools are deployed with PEIDs due to their important roles in the assembly process. Especially, the key parts of the products in assembly process are equipped with RFID tags or sensors. These PEIDs served as a mobile memory of the 'smart' product, play important roles throughout the assembly process and are retained for subsequent processes of the lifecycle (e.g. logistic, maintenance, recovery, etc.). The RFID tags are also attached to all trolleys or pallets for holding materials, including scraped materials, semi-finished and finished product assemblies.

During MOL and EOL, in order to procure the real-time field data, some tags and sensors are deployed to the appropriate positions near the location of the products and its parts (e.g. within the reading range of the reader). Meanwhile, for some parts and products that are not suitable for embedding the PEIDs, the external smart devices (e.g. smart meters and wireless sensors) are installed during the installation and debugging stages. Therefore, the PEIDs that have been deployed (during the production, assemble, and installation and debugging stages) in key parts and proper location of the products can be used to monitor and capture real-time status data of MOL and EOL stages. With the support of these PEIDs, lifecycle actors (e.g. maintenance engineers and EOL product experts) can easily access and receive the whole lifecycle status data in a ubiquitous way.

In each stage of PLM, these PEIDs are not only used for tracking the information of materials and controlling the work in process (WIP) inventories, but also for monitoring the real-time status of the product in use. Such field data from operation, maintenance and recovery processes are collected, analyzed, and fed back to improve decision-making in product design, process optimization, and shop-floor scheduling.

\subsection{Data processing and storage}

Based on configuration of the smart objects, the real-time status of manufacturing resources (Zhang et al., 2017b) and products is captured during the whole lifecycle. In order to provide reliable and unified data support for further analysis and application, the data processing and storage solution (the Component 2 of Fig. 1) must be addressed.

The distributed computing framework for Big Data processing, namely Storm (Iqbal and Soomro, 2015) and Hadoop 
(Borthakur, 2007) are used to process the real-time and non-real time lifecycle data, respectively. MapReduce computation engine provides the parallel computation (Chu et al., 2016) abilities for the large-scale lifecycle data (Dean and Ghemawat, 2004).

A large number of lifecycle data need to be stored to make a deep analysis. The quality of data is foremost before running an analysis. Therefore, data preprocessing is performed to remove the redundant and noisy data. The data processing and storage operations are briefly demonstrated as follows:

Firstly, the key attributes of lifecycle data are selected to create a lifecycle data cube, and to construct a lifecycle data warehouse so that the lifecycle Big Data could be integrated in terms of predefined logics (Zhong et al., 2015a, 2015b). The established data warehouses are used to store and manage the lifecycle data cubes, and to address the complex logic relationship among enormous lifecycle data cubes.

Secondly, the created lifecycle data cubes have a great number of redundancies, which is reduced by data cleansing operation. The information structure model (Xu et al., 2009) and RFID-Cuboid (Zhong et al., 2015a) is used for the cleansing operation. For data cleaning operation, the input is a set of lifecycle data cube from lifecycle data warehouse. The output is a sorted set of lifecycle data cube which carries important information about lifecycle status. The processes of data cleansing operation are described as follows: 1) define inputs and constraint conditions of the data cleaning operation; 2) select lifecycle data cube from lifecycle data warehouse; 3) check whether each cell in lifecycle data cube meet a predefined constraint condition; 4) delete the cell from lifecycle data cube if the cell cannot meet the condition; 5) repeat 2) to 4) until all lifecycle data cube are traversed; 6) output and return the cleaned lifecycle data cube.

Thirdly, the cleansed lifecycle data are usually still scattered. It is essential to perform the data integration operation. A unified data modeling method is used to construct the multi-granularity and multi-level data models, and to integrate the data of various lifecycle stages (Alemanni et al., 2011; Petrochenkov et al., 2015; Zhang, 2011). The concept of meta-model is introduced to build the unified data model. In this paper, five types of meta-model for lifecycle data are top-level, design, production, maintenance and meta-model. The top-level meta-model is used to describe the data model of integrated lifecycle data. Other four meta-models are used to describe the multidisciplinary data and file information, and the association relationship among different lifecycle stages. Through instantiation of the meta-models, the model sharing and data integrating are achieved.

Fourthly, the integrated data sets are typically still huge. Data analyses of huge amounts of data may make it impractical or infeasible. Therefore, a data reduction operation is performed to obtain a reduced representation of the data set that is much smaller in volume, but it must retain the integrity of the original data. The typical strategies of data reduction include dimensionality reduction and data compression. 
Fifthly, the reduced lifecycle data is transformed so that the resulting data mining process may be more efficient, and

the patterns found may be easier to understand. The strategies for data transformation include smoothing, attribute construction, aggregation, normalization and discretization, etc.

Finally, the preprocessed lifecycle data are stored in various data management systems. These data can be further shared and applied by various departments of enterprise, and in various stages of lifecycle to optimize the decision-making of PLM. The distributed data base system (DDBS) is used for managing and storing the structured lifecycle data. The XML is used for describing semi-structured lifecycle data, which is unified into a standardized data format and stored in relational database management system (RDBMS) or DDBS. The distributed data management system such as hadoop distributed file system (HDFS) (White, 2012) and the not only structured query language (NoSQL) (Cattell, 2011) are used for managing and storing the unstructured lifecycle data.

\subsection{Developing the model and performing the data mining}

By means of the Big Data analytics, the data mining model is designed to mine the hidden pattern and knowledge from real-time and historical lifecycle Big Data. Then, the knowledge base of PLM is developed by integrating the mined results of various lifecycle data. The optimization of PLM can be achieved only when the knowledge sharing is achieved in the whole lifecycle. Therefore, by integrating the knowledge base with product data and knowledge management (PDKM) system and DSS, the knowledge is shared among the whole lifecycle. As shown in the Component 3 of Fig. 1, the universal models and specific models are established according to various application requirements of PLM.

The authors of this paper developed four types of general models that included clustering, association, classification, and prediction. The relationship between lifecycle Big Data and the general model is 'many-to-many', while the relationship between the general model and mining results is 'one-to-many'. For example, the association general model can be used to evaluate the product design scheme, and to analyze the quality factor of product, etc. The prediction general model can be used to forecast the maintenance cycle in MOL, and the residual lifetime in EOL, etc.

In addition, four types of specific models are also designed. They are product design improvement, production processes optimization, maintenance strategy optimization and recovery strategy optimization. These models are built for meeting specific applications, so that the relationships among lifecycle Big Data, the special models and the mining results are 'one-to-one'. Take product design improvement as an example, if a requirement of improvement of product design is proposed by the customer, the specific model of product design improvement and related product design data are selected. By adjusting the control parameters of the model and optimizing the data sets of product design, the knowledge of product improvement design are achieved. The other three specific models are not discussed here as the 
establishing principles are similar.

The real-time lifecycle Big Data can provide timely and continuous data support for the evolution and adaptive optimization of the model, so that more accurate and a more reliable data mining model are developed. This further contributes to the more precise knowledge and rules to support the optimization of PLM.

\subsection{Big Data application for PLM}

Big Data application is used to provide real-time information and knowledge for end-users to support their appropriate operations management and facilitate optimized lifecycle decision-making. It is regarded as the top-level services of the PLM. Through the integration and sharing of the implicit knowledge of the whole lifecycle, the application services of various lifecycle stages (the Component 4 of Fig. 1) are achieved, and the adaptability and the innovation capability of enterprise are enhanced by using the integrated knowledge. For example, during MOL stage, operation, maintenance and energy consumption knowledge are integrated and shared among all lifecycle stakeholders. With the integrated knowledge, designs for maintenance and environment aspects are implemented by the design department. Consequently, the energy-efficient manufacturing and cleaner production strategy are successfully carried out in the manufacturing enterprise.

Several types of application service for different lifecycle stages are designed in this framework, namely sustainable product design, shop floor scheduling optimization, logistics optimization, process optimization, remote on-line diagnosis, predictive maintenance, energy saving, remanufacturing, reuse, etc. The real-time and historical Big Data of the whole lifecycle provides important data support for implementing these application services.

\section{Case study}

For simplicity of understanding but without losing generality of principle, a case of application of Big Data analytics in maintenance services stage was selected as a scenario, and analyzed in a systematic way. The main objective of the case analysis was to show how the business and service model was changed in association with the proposed framework for the case company, as well as what economic impacts were made by the Big Data analytics practices. In this section, firstly, major businesses of the industrial company and data collection methods of the case study were introduced. Then, the cause-effect between Big Data analytic practices and business model and economic impact for the company were analyzed from the macro and micro level.

\subsection{Case company and data sources}

The case company is specialized in manufacturing turbo-machinery (e.g. axial compressors, steam turbines), and 
providing services for and solutions with this equipment in the fields of chemical industry, metallurgical industry, power generation, environmental protection, etc. The case study aims to show association between the implementation of Big Data analytic practices and economic benefits for the company as well as analyses possible cause-and effect relation between them.

Three major businesses of the company are energy conversion device manufacturing (ECDM) which includes energy conservation and environmental protection equipment manufacturing, energy conversion system service (ECSS) which includes maintenance and upgrading service, and energy infrastructure operation (EIO) which includes sewage treatment and gas business.

With the adoption of the Big Data-driven business decision mode that involves the framework proposed in this paper, the hidden knowledge assets in the lifecycle Big Data was expected to be discovered. This knowledge would contribute to better decision-making towards business model, and to create more economic benefits.

In this case study, data was collected from multiple sources. They involved on-site observations, semi-structured interviews with middle-level managers, industrial reports, annual reports, newsletters and project reports. This allowed to enhance the validity of the constructs of the case.

\subsection{Macro level analysis of the business model and economic impact}

\subsubsection{Transformation of manufacturing and service mode}

As early as 2001, under the background of the global competition, and the policy of energy conservation and emission reduction in industrial sector, the company determined to transform its manufacturing mode from product-driven to service-driven (Gao et al., 2011). In order to provide better services for its customer, some smart sensors (e.g. pressure, velocity and temperature sensors) and smart meters (e.g. gas flow meter) are deployed to monitor the real-time operation status data (e.g. gas pressure, vibration, temperature and gas flow) of the turbo-machinery. With the increasing usage of these smart devices, a large amount of data related to product lifecycle is produced during the daily management, and collected by the company. Meanwhile, the data is multi-source and heterogeneous (e.g. produced from the different smart devices and with different data formats), and changed in a timely fashion. Therefore, the data is characterized by volume, variety, and velocity (namely 3Vs) of Big Data (Laney, 2001), and increasing at the exponential speed. This leads to a great challenge for the case company for further analysis and knowledge discovery. To address above hurdles and enhance intellectualization of the existing service system, a project of lifecycle-oriented maintenance, repair and overhaul (MRO) service based on Big Data analytics was carried out in 2012. 
After 2012 (Shaangu, 2013), the company achieved substantial increase in terms of operation revenue, especially in the ECSS business as follows. At the same time, the overall order quantity of the three major businesses was increased from 7.85 billion to 8.01 billion with year-on-year growth of $2.03 \%$ during 2012 .

As seen in Fig. 2 (a), from 2012 to 2013, the overall operation revenue of the case company increased from CNY 6.04 billion to CNY 6.29 billion, and the operation revenue of ECSS increased from CNY 0.75 billion to CNY 1.04 billion. According to the annual reports from 2011 to 2015, major reasons for these changes showed in Fig.2 were analyzed as follows:

Due to the great success of ECSS during 2012, the case company continuously developed and increased its investment in new service business from 2013 (Shaangu, 2013). By analysis of the annual reports, a causal relation between this new business investment and the changes in the revenue of ECSS were identified. As seen in Fig. 2 (a), from 2013 to 2015, the operation revenue of ECSS was decreased from CNY 1.04 to CNY 0.58. Meanwhile, other factors such as macroeconomic situation declined and downstream industries demand slowed (Shaangu, 2014a) also have the potential to have affected it;

- With the lifecycle-oriented maintenance and service mode based on Big Data analytics, the case company was able to provide specialized MRO service for its customers. It can extend the lifespan and increase the reuse rate of units. Therefore, the quantity of units sold in the market was reduced. Consequently, the operation revenue from selling ECDM was declined due to the demand of pure newly-produced products decreased (Fig. 2 (a));

- Although the lifecycle-oriented MRO service mode created more revenue for the case company in the early stage of the project, the financial data shows a reduction in the total operation revenue since 2013 due to the decrease in ECSS and ECDM (Fig. 2 (a)). However, under the pressure of both environmental protection and energy crisis, the demand of the EIO business has been rising in the downstream industry (Shaangu, 2015a). On the other hand, this prompted the growth trend of EIO over the last five years (Fig. 2 (a));

- With the application of lifecycle-oriented service mode based on Big Data analytics, maturity of core technologies and intellectualization of MRO service was improved, thus the total operation costs for ECSS were reduced (Fig. 2 (b)). Meanwhile, the operation revenues and profits for ECSS have a certain degree of decline due to the decline in macroeconomic situation between the year 2013 and 2015.

In addition to the reasons mentioned above, other aspects not taken into account in the analysis, such as organization case company. 


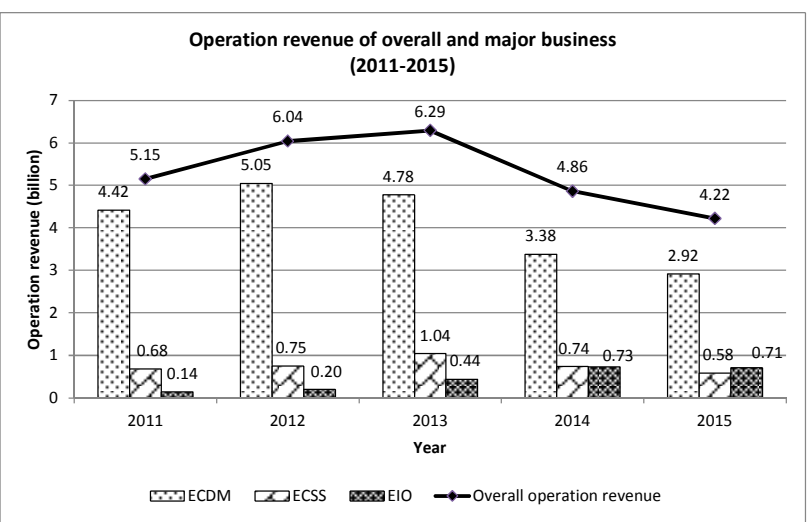

(a)

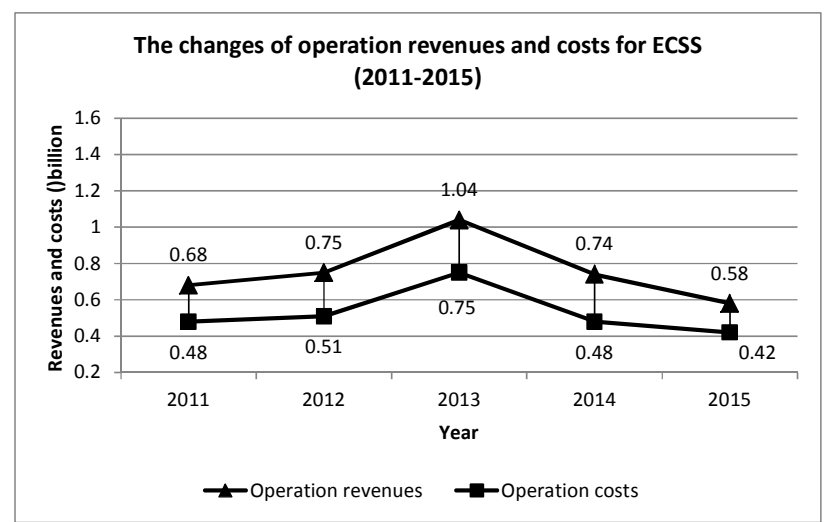

(b)

Fig.2. Statistical analysis of operation revenue and operation costs. (a) overall and three major businesses operation revenue; (b) operation revenue and costs of energy conversion system service. Data source from Shaangu annual report (Shaangu, 2015a, 2014a, 2013, 2012).

\subsubsection{Contrastive analysis of the economic impact for four enterprises}

As the 2013 and 2015 annual reports pointed out, "with the lifecycle-oriented MRO service mode based on Big Data analytics, the customer requirement can be identified more accurately, and then the company can now offer faster service to its customer. This eventually has improved customer satisfaction (overall customer satisfaction of the company is 8.73), improved the market share of the company's products, and created more profits for the company".

The sales revenue and profits of four major air blower enterprises in China from 2012 to 2014 were shown in Table 2, in which company $\mathrm{X}, \mathrm{Y}$ and $\mathrm{Z}$ still adopted the product-driven manufacturing and service mode during the period of analysis. Some findings are described as follows:

- From 2012 to 2014, with the rapid development of downstream industries, the demand for air blower products was increasing. The sales revenue in entire air blower industry maintained stable growth (CNY 18.556 vs CNY 20.491);

- During the period of this analysis, the sales revenue of the case company was lower than company X (6.042 vs $10.215,6.289$ vs 10.448 , and 4.861 vs 11.236 , in 2012,2013 , and 2014 , respectively). However, the profits of the case company were more than two times higher than company $\mathrm{X}(1.148$ vs $0.465,1.061$ vs $0.455,0.614$ vs 0.379$)$. These higher profits might be attributed to the lifecycle-oriented MRO service mode;

- According to the business information and project reports of company $\mathrm{X}, \mathrm{Y}$ and $\mathrm{Z}$ on their official website, the difference of the service strategy between the case company and other three companies can be easily observed as follows. This is the reason why the Big Data-driven business decision mode proposed in this paper can bring more profits for the case company. For company $\mathrm{Y}$ and $\mathrm{Z}$, they still adopted the product-driven manufacturing mode, so service business accounting for little in their daily businesses during the period of analysis. Meanwhile, they 
commonly adopted the traditional service strategies such as corrective maintenance and breakdown maintenance (CQGI, 2015; SBW-cn, 2015). For company X, the spare part and maintenance services are included in its daily business. However, the service strategies are different from the case company whose service businesses will elaborate in next section. For example, the spare part service is based on the subjective analyze and plan by a warehouse keeper, and the maintenance service strategies are always regular maintenance and breakdown maintenance (SBW-turbo, 2015). Compared with the other three companies, as seen in Table 2, the profits of the case company always maintained a high level. This shown that the profits of the case company were no longer from sale of pure products, but from products integrated with complete set of solutions and specialized services. By this integration, the company can enhance its ability in perceiving and predicting the market demands, develop its competitiveness, and then create more profits (Fang et al., 2016).

Table 2

Contrastive analysis of the sales revenue and profits for four major air blower enterprises (million).

\begin{tabular}{lllllll} 
Name & 2012 & & 2013 & & 2014 \\
of enterprise & Sales revenue & Profits & Sales revenue & Profits & Sales revenue & Profits \\
\cline { 2 - 7 } Case company & 6.042 & 1.148 & 6.289 & 1.061 & 4.861 & 0.614 \\
Company X & 10.215 & 0.465 & 10.448 & 0.455 & 11.236 & 0.379 \\
Company Y & 1.476 & 0.046 & 1.707 & 0.034 & 2.188 & 0.063 \\
Company Z & 0.823 & 0.016 & 0.924 & 0.014 & 2.206 & 0.015 \\
Total & 18.556 & 1.675 & 19.368 & 1.564 & 20.491 & 1.071 \\
\hline
\end{tabular}

Data source from Shaangu annual report (Shaangu, 2015a, 2014a, 2013).

\subsection{Micro level analysis of the business model}

\subsubsection{Application of the Big Data analytics approach in the case company}

With the transformation of manufacturing and service mode, and application of lifecycle-oriented MRO business model based on Big Data analytics, an intelligent and comprehensive health management for the units can be achieved by the case company (Shaangu, 2014b).

In MRO process, since the real-time operation status of the units is monitored and transmitted back to the case company, the effective and timely maintenance service strategies can be provided by Big Data analytics to make the case company acquire more value. By using Big Data analytics in their MRO process, the case company can provide accurate, high-quality, personalized units service for its customers. For instance:

1) Intelligent diagnosis and maintenance service, such as remote fault diagnosis and early fault warning;

2) Production operation optimization services, such as energy efficiency analysis and process diagnosis;

3) Equipment manufacturing intelligent services, such as zero inventory spare parts (Shaangu, 2014c). 


\subsubsection{Provision of specialized services to customers}

With the application of Big Data analytics in MRO process, the case company now possible to provide its customers with specialized services as follows. The Big Data analytics can provide aided decision support and valuable knowledge for the decision-making process of these services. These services including:

1) Remote real-time monitoring and early fault warning service;

2) Specialized remote fault diagnosis service;

3) Intelligent spare part prediction service.

\subsubsection{Changes and impacts in production and consumption patterns}

The above-mentioned services have the potential to bring about changes in production and consumption patterns that might promote the shift towards more sustainable development. Corresponding to the above three services, their impacts on production and consumption pattern are analyzed as follows, respectively:

1) With the remote real-time monitoring and early fault warning service, a predictive maintenance service can be performed, thus reliability of the units can be increased. Meanwhile, empty load energy consumption due to restart of the units and downtime can be reduced. From 2014 to 2015, the order quantity of the remote monitoring service increased from 436 to 467 (Shaangu, 2015a).

2) The remote fault diagnosis service can free customers from complicated diagnosis process of units. The accuracy of diagnosis results can be improved due to the rich experiences and complete operation data accumulation in the company.

3) The quantity of spare parts consumption can be dynamically predicted by intelligent spare part prediction service, and excessive production can be avoided. Meanwhile, inventory cost, material and energy consumption can be reduced. From 2014 to 2015, the order quantity of the spare part prediction service increased from 394 to 447, with an annual increase rate of $13.45 \%$ (Shaangu, 2015a).

In addition, under the pressure of limited natural resources and increasingly severe air quality problem, Big Data approaches have been used by the case company to learn how to decrease resource consumption and solve environmental problems. For instance, based on Big Data analytics, an industrial park with a sustainable production approach has been developed. It can provide a complete set of energy solutions (e.g. water, electricity, gas, waste treatment, etc.) for a certain industrial park (Shaangu, 2015b). Hence, reduction of material and energy consumption as well as emission in the industrial park can be realized. In this application, through Big Data analytics, the causality and hidden knowledge among the data and above-mentioned elements were discovered. These can be used to adjust production plans, reduce material consumption, and minimize water and electricity consumption. 


\subsubsection{Initiative of the Big Data analytics practices}

The case company has accumulated a lot of data related to units' field operation and customers' requirements during the implementation of the above-mentioned services. By using the Big Data analytics based on the data, the case company has proactively analyzed the operation data of the units and provided solutions to the potential problems. Besides, the company has also actively explored and excavated the customers' requirements based on the Big Data analytics (Song et al., 2016). For example:

1) Exploring the requirements of energy conservation and emissions reduction for metallurgical industry;

2) Excavating the requirements of energy recovery for coal chemical industry;

3) Identifying the requirements of personalized and on-demand services for customers'.

By the initiative exploration of the Big Data analytics practices, the case company is now also capable of providing more services to its customers, such as energy efficiency analysis, updating and rebuilding of original system, second-hand units recycling and remanufacturing service.

\subsubsection{Development of value-added business and service}

According to newsletters and project reports of the company, some value-added businesses and services have been identified and developed through Big Data analytics practices as follows.

1) Based on analysis of the historical lifecycle data of turbo-machinery, the demands in chemical industry in energy recovery were identified. A waste heat and waste pressure energy recovery equipment, namely blast furnace power recovery turbine (BPRT) (Shaangu, 2016) was creatively developed to reduce and to reuse the previously wasted energy. By applying this equipment, the energy loss can be reduced, and the energy efficiency can be improved. The market share of the BPRT is $100 \%$ in the domestic market during the period of analysis (Shaangu, 2015a).

2) Based on Big Data analytics, customers' requirements and problems existing in the units operation were mined, an energy saving equipment, namely blast furnace top-gas-pressure recovery turbine (TRT) was developed to update the old equipment and original system in metallurgical industry. By using the TRT, the electricity generating capacity of per ton of iron can be improved more than 20\% (Shaangu, 2014d), and the carbon emission can be reduced. So far, the market share of the TRT is more than 94\% (Shaangu, 2015a).

3) Through Big Data analytics, the hot-spot of customers where the units used was identified. A cross-regional service center was established to quickly respond to the personalized demand of customers. Meanwhile, shorten the period of service, and improve the efficiency of maintenance service. Moreover, the return to depot (RTD) can be avoided. On the one hand, the service costs and fuel consumption can be saved, on the other hand, the customers' satisfaction, enterprise 
brand and image, and benefit can be improved. Therefore, the customized and fast services, and the whole-set solutions can be provided for its customers.

\subsubsection{Changes of case company's roles}

With the transformation of the manufacturing and service mode, and continuous innovation of business model by Big Data analytics, the role of the company plays in industry has changed. The company now has shifted itself from a pure product manufacturer to a systematic solutions and services provider.

Aiming at the above value-added businesses and services, their effects on the changes of case company's roles is summarized as follows, respectively:

1) Undertake the $R \& D$ of customized and high quality renewable energy equipment as a solution provider;

2) Provision of low-cost and specialized updating and rebuilding services as a service provider;

3) Establishment of geographically dispersed maintenance service center as an energy saving solution and service provider.

As previously mentioned, based on the lifecycle Big Data, the predictive maintenance service, early fault warning service and spare part prediction service can be implemented. In addition to these major benefits, with the application of the proposed framework, more potential benefits can also be achieved by the case company. For example, predicting and improving the product quality, improving the production output, accurately predicting and perceiving product demand, predicting supplier performance and optimal technological parameter, etc.

\section{Managerial implications}

The case study showed the proposed framework was feasible to be adopted in industry. In particular, it was shown that the framework has potential to play a role for a manufacturer's shift to service-oriented business, contribute to enhance the economic benefits of manufacturing enterprises, and improve the environmental impact from the whole product lifecycle. This is one of the few papers to analyze the relations between BDD-PLM and its potential impacts on the economy and environment from macro and micro levels. The rest of the section describes implications to assist managers in industry to make more effective lifecycle decisions.

Firstly, the proposed framework can be used for monitoring and collecting the real-time energy consumption data from the whole product lifecycle. The manufacturing organizations can use advanced Big Data analytics to analyze the energy consumption related data, to identify the relationships among discrete lifecycle stages such as design, production, distribution, usage, maintenance, reuse, remanufacturing, and to optimize the factors that have the greatest effects on energy consumption. Thus, the proposed framework can be implemented in energy-efficient production or sustainable 
production field in general.

Secondly, after further investigating the case company, the authors of this paper found that there is the possibility of extending current applications to obtain more benefits for other manufacturing organizations. Under the proposed framework, the accessibility of the whole lifecycle Big Data can be achieved. For those energy-intensive companies, these data can be used to perform energy efficiency analyses of the equipment, of the technological processes, and for upgrading the operational systems. As a result, the technological processes and equipment can be run at higher efficiency in these manufacturing organizations.

Thirdly, leaders of other manufacturing organizations can learn from current fault diagnosis service of the case company, and research of the system diagnosis problem of equipment. Ultimately, the diagnosis service can be extended to systematic technological process diagnosis. The proposed framework provides that possibility for the manufacturing organizations to achieve systematic diagnosis objectives thanks to the availability and usefulness of the data of the whole lifecycle (especially the data of the production processes and the products in service).

\section{Conclusions}

Advanced information technologies are increasingly utilized in manufacturing enterprises for their daily production and management. As a result, the PLM process produces a large amount of potentially useful data. Much valuable data is gathered and may be turned into decision-support knowledge if the Big Data is properly analyzed and the hidden knowledge is utilized properly. Therefore, lifecycle Big Data management and mining receives increasing attention by leaders of manufacturing enterprises. They are eager to implement solutions based upon full use of the lifecycle Big Data. However, several challenges must be addressed:

- How to sense and to capture the lifecycle Big Data completely and in a timely fashion;

- How to unify management and storage the multi-source heterogeneous lifecycle Big Data;

- How to effectively mine and utilize the knowledge from lifecycle Big Data.

To address these challenges, the authors designed and tested the key components of a BDD-PLM infrastructure framework to provide new tools for the leaders of manufacturing enterprises to optimize their PLM decisions. Several significant contributions were made. Firstly, the configuration method of PEIDs for sensing and capturing the lifecycle Big Data was designed. It can be used to actively sense the real-time data of the manufacturing processes and to collect lifecycle data of products, which can provide valuable data to support managers PLM decisions. Secondly, the concept of the data warehouse was developed to create the lifecycle data cube so that the multi-source heterogeneous lifecycle Big Data can be effectively processed and utilized. A unified data modeling method was introduced for integrating the data of 
the whole lifecycle, so that the lifecycle Big Data can be used by all departments of the enterprises. Thirdly, according to different application requirements of PLM, four types of general and special models for lifecycle Big Data mining were designed. These helped the manufacturing enterprise to uncover and to utilize the hidden knowledge and the rules of lifecycle Big Data. Finally, a case study was presented to show the proof-of-concept application of the proposed BDD-PLM framework. The cause and effect relation between the implementation of Big Data analytic practices and economic benefits for the company was analyzed in macro and micro levels. The results showed that the proposed framework was feasible to be adopted in industry. In addition, the key findings from the case study were summarized as managerial implications, which can be used as a guideline by manufacturers to perform energy and material's efficiency improvements and fault diagnosis decisions in PLM.

The main scientific contributions of this paper are, on the one hand, to describe a means of interrelation between Big Data and PLM, which traditionally was tackled in a separate way or seldom considered; on the other hand, an innovative framework of BDD-PLM was proposed. The proposed framework can provide a theoretical and practical infrastructure for manufacturing enterprises to optimize the decisions of PLM based upon lifecycle Big Data.

Future research will focus upon the following four aspects. Firstly, the discovered knowledge and association relationship will be used for supporting the lifecycle decisions. By using the data mining theory, a mathematical model will be established to identify the hidden knowledge and rules from the multi-source heterogeneous lifecycle Big Data. Secondly, the data of various lifecycle stages have their own characteristics. Therefore, the study can be further concentrated on the different algorithms of data preprocessing for different lifecycle Big Data. Thirdly, the mined knowledge of lifecycle Big Data will be useful not only for one stage of the lifecycle, but also for the whole lifecycle. The problem of integration of the mined knowledge will be further studied given different PLM application requirements. Finally, based on the lifecycle Big Data, how to mine the customer requirements and then to incorporate the results to product design will also be studied in the future.

\section{Acknowledgements}

The authors would like to acknowledge the financial supports of National Science Foundation of China (51675441) and the 111 Project Grant (B13044). This research is also supported in part by the Circularis (Circular Economy through Innovating Design) project (No. 2016-03267) and the Simon (New Application of AI for Services in Maintenance towards a Circular Economy) project (No. 2017-01649) funded by VINNOVA, Sweden's Innovation Agency.

\section{References}

Alemanni, M., Destefanis, F., Vezzetti, E., 2011. Model-based definition design in the product lifecycle management 
scenario. Int. J. Adv. Manuf. Technol. 52, 1-14. doi:10.1007/s00170-010-2699-y

Auschitzky, E., Hammer, M., Rajagopaul, A., 2014. How big data can improve manufacturing. McKinsey 1-4.

Borthakur, D., 2007. The hadoop distributed file system: Architecture and design. Hadoop Proj. Website 11, 21.

Cattell, R., 2011. Scalable SQL and NoSQL data stores. Acm Sigmod Rec. 39, 12-27. doi:10.1145/1978915.1978919

Chen, M., Mao, S., Liu, Y., 2014. Big data: A survey. Mob. Networks Appl. 19, 171-209. doi:10.1007/s11036-013-0489-0

Chen, Y.S., Chen, C.H., Lai, C.J., 2012. Extracting performance rules of suppliers in the manufacturing industry: An empirical study. J. Intell. Manuf. 23, 2037-2045. doi:10.1007/s10845-011-0530-8

Chu, J.F., Wu, J., Song, M.L., 2016. An SBM-DEA model with parallel computing design for environmental efficiency evaluation in the big data context: a transportation system application. Ann. Oper. Res. 1-20. doi:10.1007/s10479-016-2264-7

CQGI, 2015. Service of industrial equipment. http://www.cqgic.com/aspx/ch/list.aspx?classid=145 (accessed 2016.08.15, in Chinese).

Dean, J., Ghemawat, S., 2004. MapReduce: Simplified Data Processing on Large Clusters. Proc. OSDI - Symp. Oper. Syst. Des. Implement. 137-149. doi:10.1145/1327452.1327492

Denkena, B., Schmidt, J., Krüger, M., 2014. Data Mining Approach for Knowledge-based Process Planning. Procedia Technol. 15, 406-415. doi:10.1016/j.protcy.2014.09.095

Fang, K., Jiang, Y., Song, M., 2016. Customer profitability forecasting using Big Data analytics: A case study of the insurance industry. Comput. Ind. Eng. 101, 554-564. doi:10.1016/j.cie.2016.09.011

Ferrer, G., Heath, S.K., Dew, N., 2011. An RFID application in large job shop remanufacturing operations. Int. J. Prod. Econ. 133, 612-621. doi:10.1016/j.ijpe.2011.05.006

Gao, J., Yao, Y., Zhu, V.C.Y., Sun, L., Lin, L., 2011. Service-oriented manufacturing: A new product pattern and manufacturing paradigm. J. Intell. Manuf. 22, 435-446. doi:10.1007/s10845-009-0301-y

Garg, K., Kannan, D., Diabat, A., Jha, P.C., 2015. A multi-criteria optimization approach to manage environmental issues in closed loop supply chain network design. J. Clean. Prod. 100, 297-314. doi:10.1016/j.jclepro.2015.02.075

Geng, X., Chu, X., Zhang, Z., 2010. A new integrated design concept evaluation approach based on vague sets. Expert Syst. Appl. 37, 6629-6638. doi:10.1016/j.eswa.2010.03.058

Gonzalez, E.D.R.S., Maculan, N., Huatuco, L.H., Montoya-Torres, J.R., Diabat, A., de Almeida, C.M.V.B., Giannetti, B., Huisingh, D., 2013. Decision-support models and tools for helping to make real progress to more sustainable societies. J. Clean. Prod. 59, 3-4. doi:10.1016/j.jclepro.2013.05.031

Gonzalez, E.D.R.S., Sarkis, J., Huisingh, D., Huatuco, L.H., Maculan, N., Montoya-Torres, J.R., De Almeida, C.M.V.B., 2015. Making real progress toward more sustainable societies using decision support models and tools: Introduction to the special volume. J. Clean. Prod. 105, 1-13. doi:10.1016/j.jclepro.2015.05.047

Guo, Z.X., Ngai, E.W.T., Yang, C., Liang, X., 2015. An RFID-based intelligent decision support system architecture for production monitoring and scheduling in a distributed manufacturing environment. Int. J. Prod. Econ. 159, 16-28. doi:10.1016/j.ijpe.2014.09.004

Hazen, B.T., Boone, C.A., Ezell, J.D., Jones-Farmer, L.A., 2014. Data quality for data science, predictive analytics, and 
big data in supply chain management: An introduction to the problem and suggestions for research and applications. Int. J. Prod. Econ. 154, 72-80. doi:10.1016/j.ijpe.2014.04.018

Hofmann, E., 2015. Big data and supply chain decisions: the impact of volume, variety and velocity properties on the bullwhip effect. Int. J. Prod. Res. 7543, 1-19. doi:10.1080/00207543.2015.1061222

Huang, G.Q., Qu, T., Zhang, Y., Yang, H.D., 2012. RFID- enabled product-service system for automotive part and accessory manufacturing alliances. Int. J. Prod. Res. 50, 3821-3840. doi:10.1080/00207543.2011.592863

Iqbal, M.H., Soomro, T.R., 2015. Big data analysis: Apache storm perspective. Int. J. Comput. Trends Technol. 9-14.

Jacobs, A., 2009. The Pathologies of Big Data. Queue 7, 10. doi:10.1145/1563821.1563874

Jaggi, A.S., Sawhney, R.S., Balestrassi, P.P., Simonton, J., Upreti, G., 2014. An experimental approach for developing radio frequency identification (RFID) ready packaging. J. Clean. Prod. 85, 371-381. doi:10.1016/j.jclepro.2014.08.105

Jun, H.-B., Shin, J.-H., Kim, Y.-S., Kiritsis, D., Xirouchakis, P., 2009. A framework for RFID applications in product lifecycle management. Int. J. Comput. Integr. Manuf. 22, 595-615. doi:10.1080/09511920701501753

Jun, H.-B., Shin, J.-H., Kiritsis, D., Xirouchakis, P., 2007. System architecture for closed-loop PLM. Int. J. Comput. Integr. Manuf. 20, 684-698. doi:10.1080/09511920701566624

Kiritsis, D., 2011. Closed-loop PLM for intelligent products in the era of the Internet of things. CAD Comput. Aided Des. 43, 479-501. doi:10.1016/j.cad.2010.03.002

Köksal, G., Batmaz, I., Testik, M.C., 2011. A review of data mining applications for quality improvement in manufacturing industry. Expert Syst. Appl. 38, 13448-13467. doi:10.1016/j.eswa.2011.04.063

Kumar, A., Rahman, S., 2014. RFID-enabled process reengineering of closed-loop supply chains in the healthcare industry of Singapore. J. Clean. Prod. 85, 382-394. doi:10.1016/j.jclepro.2014.04.037

Kusiak, A., Verma, A., 2011. Prediction of Status Patterns of Wind Turbines: A Data-Mining Approach. J. Sol. Energy Eng. 133, 11008. doi:10.1115/1.4003188

Laney, D., 2001. 3-D Data Management:Controlling Data Volume, Velocity and Variety. META Gr. Res. Note 1-4.

Lee, B.E., Suh, S.H., 2009. An architecture for ubiquitous product life cycle support system and its extension to machine tools with product data model. Int. J. Adv. Manuf. Technol. 42, 606-620. doi:10.1007/s00170-008-1628-9

Lee, S.G., Ma, Y.S., Thimm, G.L., Verstraeten, J., 2008. Product lifecycle management in aviation maintenance, repair and overhaul. Comput. Ind. 59, 296-303. doi:10.1016/j.compind.2007.06.022

Leitão, P., Colombo, A.W., Karnouskos, S., 2016. Industrial automation based on cyber-physical systems technologies: Prototype implementations and challenges. Comput. Ind. 81, 11-25. doi:10.1016/j.compind.2015.08.004

Li, J., Tao, F., Cheng, Y., Zhao, L., 2015. Big Data in product lifecycle management. Int. J. Adv. Manuf. Technol. 81, 667-684. doi:10.1007/s00170-015-7151-X

Liu, Y., 2013. Sustainable competitive advantage in turbulent business environments. Int. J. Prod. Res. 51, $2821-2841$. doi:10.1080/00207543.2012.720392

Liu, Y., Liang, L., 2015. Evaluating and developing resource-based operations strategy for competitive advantage: an exploratory study of Finnish high-tech manufacturing industries. Int. J. Prod. Res. 53, 1019-1037. doi:10.1080/00207543.2014.932936 
Ma, J., Kwak, M., Kim, H.M., 2014. Demand trend mining for predictive life cycle design. J. Clean. Prod. 68, 189-199. doi:10.1016/j.jclepro.2014.01.026

Magro, M.C., Pinceti, P., 2009. A confirmation technique for predictive maintenance using the Rough Set Theory. Comput. Ind. Eng. 56, 1319-1327. doi:10.1016/j.cie.2008.07.024

McAfee, A., Brynjolfsson, E., McAfee, Andrew; Brynjolfsson, E., McAffee, A., Brynjolfsson, E., 2012. Big Data: The Management Revolution. Harv. Bus. Rev. 90, 60-68. doi:00475394

Nativi, J.J., Lee, S., 2012. Impact of RFID information-sharing strategies on a decentralized supply chain with reverse logistics operations. Int. J. Prod. Econ. 136, 366-377. doi:10.1016/j.ijpe.2011.12.024

Opresnik, D., Taisch, M., 2015. The value of big data in servitization. Int. J. Prod. Econ. 165, 174-184. doi:10.1016/j.ijpe.2014.12.036

Petrochenkov, A.B., Bochkarev, S. V, Ovsyannikov, M. V, Bukhanov, S.A., 2015. Construction of an ontological model of the life cycle of electrotechnical equipment. Russ. Electr. Eng. 86, 320-325. doi:10.3103/S1068371215060115

Poon, T.C., Choy, K.L., Chow, H.K.H., Lau, H.C.W., Chan, F.T.S., Ho, K.C., 2009. A RFID case-based logistics resource management system for managing order-picking operations in warehouses. Expert Syst. Appl. 36, 8277-8301. doi:10.1016/j.eswa.2008.10.011

Premalatha, S., Baskar, N., 2012. Implementation of supervised statistical data mining algorithm for single machine scheduling. J. Adv. Manag. Res. 9, 170-177. doi:10.1108/09727981211271913

Purarjomandlangrudi, A., Ghapanchi, A.H., Esmalifalak, M., 2014. A data mining approach for fault diagnosis: An application of anomaly detection algorithm. Measurement 55, 343-352. doi:10.1016/j.measurement.2014.05.029

Sari, K., 2010. Exploring the impacts of radio frequency identification (RFID) technology on supply chain performance. Eur. J. Oper. Res. 207, 174-183. doi:10.1016/j.ejor.2010.04.003

SBW-cn, 2015. Services to be provided. http://www.sbw-cn.com/fw/web/index.html (accessed 2016.08.15, in Chinese).

SBW-turbo, 2015. Service. http://www.shengu.com.cn/article_read_87.html (accessed 2016.08.15, in Chinese).

Shaangu, 2016. Energy conversion equipment manufacturing. http://www.shaangu.com/ENGLISH/Businesses.jsp?urltype=tree.TreeTempUrl\&wbtreeid=1102 (accessed 2016.08.08, in Chinese).

Shaangu, 2015a. Shaangu annual report. http://gg.cfi.cn/DetailsInfo2.aspx?dm=gpdm\&type=cb\&id=515100626444 (accessed 2016.08.08, in Chinese).

Shaangu, 2015b. Shaangu news. http://www.ccin.com.cn/ccin/news/2015/09/06/322673.shtml (accessed 2017.02.25, in Chinese).

Shaangu, 2014a. Shaangu annual report. http://gg.cfi.cn/DetailsInfo2.aspx?dm=gpdm\&type=cb\&id=479981426062 (accessed 2016.08.08, in Chinese).

Shaangu, 2014b. MRO service platform. http://in-tech.shaangu-group.com/nry.jsp?urltype=news.NewsContentUrl\&wbtreeid=1103\&wbnewsid=1020 (accessed 2016.08.21, in Chinese).

Shaangu, 2014c. Intelligent service. http://in-tech.shaangu-group.com/nry.jsp?urltype=news.NewsContentUrl\&wbtreeid=1104\&wbnewsid=1021 (accessed 2016.08.21, in Chinese). 
Shaangu, 2014d. Shaangu news.

http://www.shaangu-group.com/content.jsp?urltype=news. NewsContentUrl\&wbnewsid=4519\&wbtreeid=1014 (accessed 2016.08.21, in Chinese).

Shaangu, 2013. Shaangu annual report. http://gg.cfi.cn/DetailsInfo2.aspx?dm=gpdm\&type=cb\&id=446809824548 (accessed 2016.08.02, in Chinese).

Shaangu, 2012. Shaangu annual report. http://gg.cfi.cn/DetailsInfo2.aspx?dm=gpdm\&type=cb\&id=415267223790 (accessed 2016.08.02, in Chinese).

Shrouf, F., Miragliotta, G., 2015. Energy management based on Internet of Things: practices and framework for adoption in production management. J. Clean. Prod. 100, 235-246. doi:10.1016/j.jclepro.2015.03.055

Song, M., Cen, L., Zheng, Z., Fisher, R., Liang, X., Wang, Y., Huisingh, D., 2017. How would big data support societal development and environmental sustainability? Insights and practices. J. Clean. Prod. 142,Part 2, 489-500. doi:http://dx.doi.org/10.1016/j.jclepro.2016.10.091

Song, M., Wang, J., Zhao, J., 2016. Coal endowment, resource curse, and high coal-consuming industries location: Analysis based on large-scale data. Resour. Conserv. Recycl. doi:http://dx.doi.org/10.1016/j.resconrec.2016.08.005

Syed, A.R., Gillela, K., Venugopal, C., 2013. The Future Revolution on Big Data. Int. J. Adv. Res. Comput. Commun. Eng. 2, 2446-2451.

Wan, H. Da, Gonnuru, V.K., 2013. Disassembly planning and sequencing for end-of-life products with RFID enriched information. Robot. Comput. Integr. Manuf. 29, 112-118. doi:10.1016/j.rcim.2012.05.001

Wang, J., Luo, Z., Wong, E.C., 2010. RFID-enabled tracking in flexible assembly line. Int. J. Adv. Manuf. Technol. 46, 351-360. doi:10.1007/s00170-009-2102-z

White, T., 2012. Hadoop: The definitive guide. Online 54, 258. doi:citeulike-article-id:4882841

Wu, K.J., Liao, C.J., Tseng, M.L., Lim, M.K., Hu, J., Tan, K., 2017. Toward sustainability: Using big data to explore the decisive attributes of supply chain risks and uncertainties. J. Clean. Prod. 142,Part 2, 663-676. doi:10.1016/j.jclepro.2016.04.040

Xu, D.F., Li, Q., Jun, H.B., Browne, J., Chen, Y.L., Kiritsis, D., 2009. Modelling for product information tracking and feedback via wireless technology in closed-loop supply chains. Int. J. Comput. Integr. Manuf. 22, 648-670. doi:10.1080/09511920701675755

Zhang, S., 2011. Total object unified model driven architecture of product lifecycle management. Int. J. Prod. Lifecycle Manag. 5, 242-252. doi:10.1504/IJPLM.2011.043190

Zhang, Y., Qian, C., Lv, J., Liu, Y., 2016. Agent and cyber-physical system based self-organizing and self-adaptive intelligent shopfloor. IEEE Trans. Ind. Informatics. doi:10.1109/TII.2016.2618892

Zhang, Y., Ren, S., Liu, Y., Si, S., 2017a. A big data analytics architecture for cleaner manufacturing and maintenance processes of complex products. J. Clean. Prod. 142,Part 2, 626-641. doi:10.1016/j.jclepro.2016.07.123

Zhang, Y., Zhang, G., Qu, T., Liu, Y., Zhong, R.Y., 2017b. Analytical target cascading for optimal configuration of cloud manufacturing services. J. Clean. Prod. 151, 330-343. doi:http://dx.doi.org/10.1016/j.jclepro.2017.03.027

Zhang, Y., Zhang, G., Wang, J., Sun, S., Si, S., Yang, T., 2015. Real-time information capturing and integration framework of the internet of manufacturing things. Int. J. Comput. Integr. Manuf. 28(8), 811-822. doi:10.1080/0951192X.2014.900874 
Zhang, Z., Cheng, H., Chu, X., 2010. Aided analysis for quality function deployment with an Apriori-based data mining approach. Int. J. Comput. Integr. Manuf. 23, 673-686. doi:10.1080/0951192X.2010.492840

Zhao, R., Liu, Y., Zhang, N., Huang, T., 2017. An optimization model for green supply chain management by using a big data analytic approach. J. Clean. Prod. 142,Part 2, 1085-1097. doi:10.1016/j.jclepro.2016.03.006

Zhong, R.Y., Dai, Q.Y., Qu, T., Hu, G.J., Huang, G.Q., 2013. RFID-enabled real-time manufacturing execution system for mass-customization production. Robot. Comput. Integr. Manuf. 29, 283-292.

Zhong, R.Y., Huang, G.Q., Lan, S., Dai, Q.Y., Chen, X., Zhang, T., 2015a. A big data approach for logistics trajectory discovery from RFID-enabled production data. Int. J. Prod. Econ. 165, 260-272. doi:10.1016/j.ijpe.2015.02.014

9 Zhong, R.Y., Xu, C., Chen, C., Huang, G.Q., 2015b. Big Data Analytics for Physical Internet-based intelligent 


\section{Highlights}

$>$ A framework for Big Data driven product lifecycle management was proposed.

$>$ Macro and micro level analysis of business model and economic impact were conducted.

> The proposed framework verified by case study was feasible to be adopted in industry.

$>$ Managerial implications in energy saving and fault diagnosis were summarized. 